\title{
Langerhans cell histiocytosis in a 5-month-old baby
}

\author{
Neil Chanchlani MBChB MSc, Simon C. Parke MBChB, James W. Hart MBBS
}

Cite as: CMAJ 2021 January 4;193:E23. doi: 10.1503/cmaj.201151

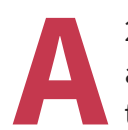
2-month-old boy presented to his family physician with areas of petechiae, confluent erythema, crusted pustules and hyperemia in the skin creases behind his ears, and in the neck, axilla and groin creases. The family physician diagnosed infected eczema and treated him with topical betamethasone dipropionate and oral amoxicillin, but the rash did not improve.

At 5 months of age, while growing well along centiles, the patient presented to hospital with worsening skin changes (Figure 1) and a 2-day history of fever, bilious vomiting, diarrhea and edema. Blood test results were as follows: hemoglobin, 84 (normal 95-135) g/L; mean corpuscular volume, 86 (normal 74-108) fL; white blood cell count, 11.4 (normal $6.0-17.5) \times 10^{9} / \mathrm{L}$; platelet count, 107 (normal 150-400) $\times 10^{9} / \mathrm{L}$; bilirubin, 9 (normal <21) $\mu \mathrm{mol} / \mathrm{L}$; and albumin, 17 (normal 30-45) g/L. Renal and liver function tests were normal. A lytic lesion on the patient's left proximal femur was found on a skeletal survey.

Skin and duodenal biopsies were positive for Langerhans cell histiocytosis, and we identified involvement in multiple sites (dermatological, hematological, bone and gastrointestinal). The patient responded poorly to vinblastine and prednisolone; as he tested positive for the BRAF V600E mutation, he was started on dabrafenib, a BRAF kinase inhibitor, with clinical improvement.

Langerhans cell histiocytosis is a proliferative disorder with an incidence of 5.8 cases per million among children. ${ }^{1}$ It is characterized by an accumulation of antigen-presenting dendritic (Langerhans) cells. ${ }^{1}$ A rash, often misdiagnosed as eczema, allergy or scabies, is a common presenting feature. ${ }^{2}$ Patients may also present with isolated, painful lytic bone lesions, typically in the skull; polyuria and polydipsia secondary to diabetes insipidus; chronic otitis media; or features of multisite disease, including bone marrow suppression (cytopenia), lymphadenopathy and hepatosplenomegaly. ${ }^{3}$ Complications and death occur in up to $50 \%$ of cases. ${ }^{4}$

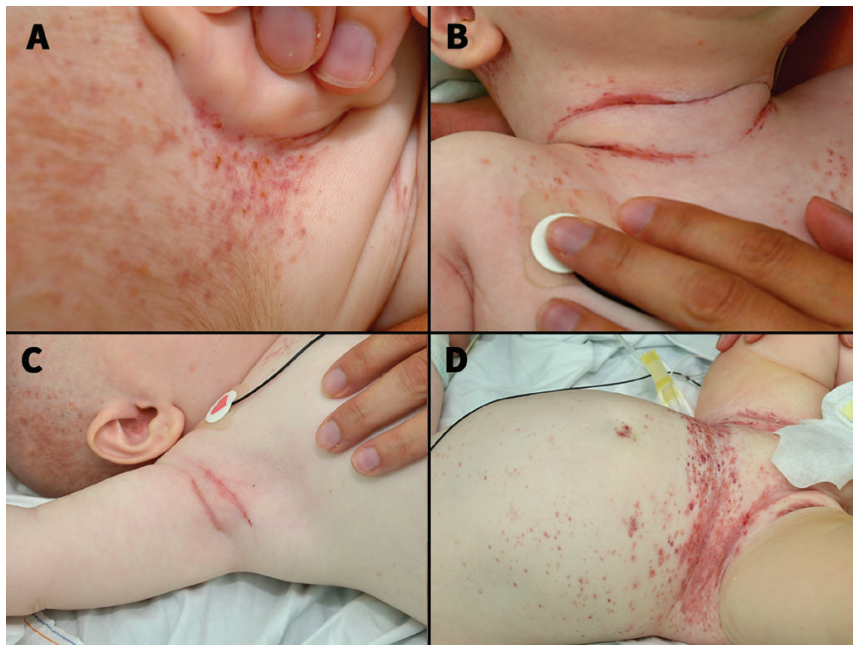

Figure 1: Photographs of a 5-month-old boy showing petechiae, confluent erythema, crusted papules and hyperemia in the skin creases involving the ears (A), neck (B), axilla (C) and groin (D). Vesicles and ulcers in the ear and groin creases, and areas of maceration in the neck, axilla and groin are seen.

Red flags for considering diagnoses other than eczema include a lack of response to topical steroids, fever of unknown origin, generalized petechiae unrelated to excoriation, an atypical pattern (e.g., involvement of axilla and groin) or persistent irritability. ${ }^{3}$

\section{References}

1. Rigaud C, Barkaoui MA, Thomas C, et al. Langerhans cell histiocytosis: therapeutic strategy and outcome in a 30-year nationwide cohort of 1478 patients under 18 years of age. Br J Haematol 2016;174:887-98.

2. Krooks J, Minkov M, Weatherall AG. Langerhans cell histiocytosis in children: Diagnosis, differential diagnosis, treatment, sequelae, and standardized followup. J Am Acad Dermatol 2018;78:1047-56.

3. Haupt R, Minkov M, Astigarraga I, et al. Langerhans cell histiocytosis (LCH): guidelines for diagnosis, clinical work-up, and treatment for patients till the age of 18 years. Pediatr Blood Cancer 2013;60:175-84.

4. Allen CE, Merad M, McClain KL. Langerhans-cell histiocytosis. N Engl J Med 2018;379:856-68

\begin{abstract}
Competing interests: Neil Chanchlani receives funding from Crohn's and Colitis UK through a clinical research fellowship. He is an associate editor of CMAJ, but not involved in the review or decision to accept this manuscript for publication. No other competing interests were declared.

This article has been peer reviewed.
\end{abstract}

The authors have obtained parental consent.
Affiliation: Royal Devon and Exeter Hospital, Exeter, UK

Content licence: This is an Open Access article distributed in accordance with the terms of the Creative Commons Attribution (CC BY-NC-ND 4.0) licence, which permits use, distribution and reproduction in any medium, provided that the original publication is properly cited, the use is non-commercial (i.e. research or educational use), and no modifications or adaptations are made. See: https://creativecommons.org/ licenses/by-nc-nd/4.0/

Disclaimer: Neil Chanchlani is an associate editor for CMAJ and was not involved in the editorial decision-making process for this article.

Correspondence to: Neil Chanchlani, nchanchlani@doctors.org.uk 